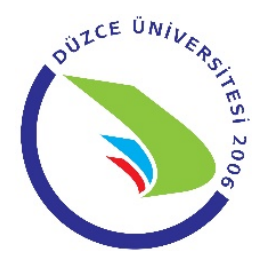

\title{
Hemşirelik Öğrencilerinin Sağlıklı Yaşam Biçimi Davranışları Düzeyinin Değerlendirilmesi
}

\author{
Cevriye YÜKSEL KAÇAN ${ }^{1}$, Özlem ÖRSAL國 ${ }^{2}$
}

ÖZ

Amaç: Tanımlayıcı olarak planlanan bu araştırmada, hemşirelik öğrencilerinin sağlıklı yaşam biçimi davranışları düzeyini belirlemek amaçlanmıştır.

Gereç ve Yöntemler: Araştırmanın evrenini 2016-2017 eğitim öğretim yılı bahar yarıyılında bir üniversitede aynı dönem içinde hemşirelik programına kayıtlı olan $1,2,3$ ve 4 . sınıf öğrencileri oluşturmuştur $(n=619)$. Çalışmada örneklem seçimine gidilmemiş, tüm öğrencilere ulaşılması hedeflenmiştir. Toplam 619 öğrencinin 486'sı çalışmaya katılmayı kabul etmiş ve evrenin \%79'una ulaşılmıştır. Veri toplamada; sosyo demografik veri toplama formu ve Sağlıklı Yaşam Biçimi Davranışları Ölçeği II kullanılmıştır. Çalışmanın yapılabilmesi için gerekli yasal izinler alınmışıır. Çalışmadaki verilerin tanımlayıcı istatistikleri ve frekans dağılımları elde edilmiştir. Parametrik test varsayımları kontrol edildikten sonra gruplar arası karşılaştırmalarda One Way ANOVA (post hoc: Bonferroni test) ve Student $t$ testi kullanılmıştır. Ölçeğin güvenirlik analizi yapılmış ve Cronbach alfa değeri hesaplanmıştır.

Bulgular: Çalışma sonuçlarına göre öğrencilerin sağlıklı yaşam biçimi toplam puan ortalaması $131.02 \pm 18.98$ olup, en yüksek puan ortalaması manevi gelişim $(27.13 \pm 3.98)$, en düşük puan ortalaması fiziksel aktivite (17.28 \pm 4.85$)$ alt boyutundan alınmıştır. Çalışmada cinsiyet ve mezun olunan lise ile ölçek toplam puanı arasında anlamlı ilişki bulunmazken $(\mathrm{p}>0.05)$, sınıf düzeyi ile olan ilişki istatistiksel olarak anlamlı bulunmuştur $(\mathrm{p}<0.05)$. Sağlıklı Yaşam Biçimi Davranışları Ölçeği toplam puan ortalaması ve sağlı sorumluluğu, fiziksel aktivite, beslenme ve stres yönetimi alt boyut puan ortalamaları, 2.sinıf öğrencilerde daha düşük bulunmuştur.

Sonuç: Araştırma sonuçlarına göre hemşirelik öğrencilerinin ölçek puan ortalamalarının yüksek olduğu görülmektedir. Anahtar Kelimeler: Hemşirelik öğrencileri; sağlık; sağlık davranışı.

\section{Evaluation of Healthy Life Style Behaviors Level of Nursing Students}

\begin{abstract}
Aim: In this descriptive study, it was aimed to determine the level of healthy lifestyle behaviors of nursing students. Material and Methods: The universe of the study was composed of 1, 2, 3 and 4 year students enrolled in a nursing program at a university in the spring semester of 2016-2017 academic year $(n=619)$. The sample was not selected and it was aimed to reach all students. 486 of the 619 students agreed to participate in the study and reached $79 \%$ of the universe. In data collection; socio-demographic data collection form and Healthy Lifestyle Behavior Scale II were used. The necessary legal permits were obtained for the study. Descriptive statistics and frequency distributions of the data were obtained. After checking the parametric test assumptions, One Way ANOVA (post hoc: Bonferroni test) and Student's t test was used for intergroup comparisons. The reliability analysis of the scale was performed and Cronbach alpha value was calculated.

Results: According to the results of the study, the mean total score of the Healthy Lifestyle Behavior Scale II was $131.02 \pm 18.98$. While there was no significant relation between gender and graduated high school and total score of the study $(\mathrm{p}>0.05)$, the relationship with grade level was statistically significant $(\mathrm{p}<0.05)$. The mean total score of the Healthy Lifestyle Behavior Scale and the health responsibility, physical activity, nutrition and stress management subscale scores were lower in the second year students.
\end{abstract}

1 Uludağ Üniversitesi, Sağıık Bilimleri Fakültesi, Hemşirelik Bölümü, Halk Sağlığı Hemşireliği A.D., Bursa, Türkiye

2 Eskişehir Osmangazi Üniversitesi, Eskişehir Sağlık Bilimleri Fakültesi, Hemşirelik Bölümü, Halk Sağlığı Hemşireliği A.D., Eskişehir, Türkiye

Sorumlu Yazar / Corresponding Author: Cevriye YÜKSEL KAÇAN, e-mail: cevriyekacan@uludag.edu.tr

Geliş Tarihi / Received: 06.12.2018, Kabul Tarihi / Accepted: 24.01.2019 
Conclusion: According to the results of the research, it is seen that the mean scores of the nursing students are above the middle level of the scale.

Keywords: Nursing students; health; health behavior.

\section{GIRIŞ}

İnsanoğlunun var olduğu ilk günden bugüne, en çok üzerinde durulan, en çok çalışılan ve hala önemli araştırma alanlarından birini teşkil eden "sağlık" kavramı; doğumdan ölüme kadar en üst seviyedeki optimal iyilik halinin varlığı olarak tanımlanabilir (1). Sağlıklı yaşam biçimini ise; "kişinin sağlığını etkileyebilecek olan bütün davranışlarını kontrol ederek, günlük yaşantısında kendi sağlık durumuna uygun olan tutumları seçebilmesi" olarak tanımlamak mümkündür $(2,3)$. Yeterli ve dengeli beslenmeyi, stres yönetimini, düzenli egzersiz yapmayı, manevi gelişimi, kişilerarası ilişkileri ve bireyin sağlığını koruma ve geliştirmesine ilişkin sorumluluk almasını kapsayan sağlıklı yaşam biçimi davranışlarının $(1,2,4)$; tüm toplum üyeleri tarafindan kazanılması ve sürdürülmesi, genel toplum sağlığı açısından önem arz etmektedir (5). Bu noktada; toplumun sağlığını koruma, sürdürme ve geliştirmedeki rolü gün geçtikçe daha sık vurgulanmaya başlayan hemşirelerin, kuşkusuz sağlıklı yaşam biçimi davranışları konusunda yetkin ve bilgili olması beklenmektedir $(5,6)$.

Üniversite yaşamı, bireylerin yaşamlarında önemli değişimlerin yaşandığı, mesleki eğitimin yanı sıra kişisel sağlık davranışları kazanımında ve sağlıklı yaşam biçimi davranışının şekillenmesinde önemli bir süreç olarak karşımıza çıkmaktadır $(4,5)$. Hemşirelik öğrencilerinin eğitim programlarında yer alan sağlıklı ve hasta bireyi tanıma/tanılamaya yönelik konular, eğitim süreci içinde öğrencilere kişisel gelişim, öz bakım, tutum ve davranış anlamında pek çok beceri geliştirmeye olanak sağlamaktadır (7). Hemşirelik öğrencileri, geleceğin sağlık bakım hizmeti sunucuları olarak (7) sağlığı koruma ve geliştirme konusunda topluma rol model olacak meslek adaylarıdır (2). Hemşirelik öğrencisi, mezun olduğunda etkili ve verimli bakım hizmeti sunmak için öncelikle kendi kişisel sağlığını korumaya ilişkin doğru tutumları geliştirmek zorundadır $(2,8,9)$. Hemşirelerin; toplum, aile ve bireylere sağlıklı yaşam biçimi doğrultusunda rehber olabilmeleri ve bu anlamda sağlığ koruma sürdürme ve geliştirmedeki rollerini icra edebilmeleri için, eğitim süreçlerinde bu kavramlara yönelik kişisel gelişimlerini tamamlamaları gerekmektedir (2,10). Dünya Sağlık Örgütü (WHO), sağlığı geliştirme ve sağlıklı yaşam biçimi davranışlarının kazandırılması konusunda temel insan gücü olarak hemşireleri işaret ederken, hemşirelerin bu konuların önemini kavramalarına, sağlıklı yaşam biçimi davranışları konusunda yol gösterici bir model olmaları gerektiğine vurgu yapmaktadır (11-13). Bu nedenle WHO tarafından belirlenen "21.Yüzyılda Herkes İçin Sağlık Hedefleri"nde sağlığı geliştirme ve sağlıklı yaşam biçimi üzerinde önemle durulması, hemşirelik eğitiminin bu alanlar üzerine daha fazla dayandırılması gerektiği görüşü hız kazanmıştır (5).

$\mathrm{Bu}$ çalışmada, sağlıklı yaşam biçimi davranışlarının giderek önem kazandığ 1 ve konuyla ilgili farkındalığın arttığı dünya sağlık sistemlerinde, sağlık hizmeti sunumunda primer olarak rol alacak hemşirelik öğrencilerinin sağlıklı yaşam biçimi davranışları düzeyini belirlemek amaçlanmıştır.

\section{GEREÇ VE YÖNTEMLER}

Araştırmanın Tasarımı: Tanımlayıcı tipte yapılmıştır.

Araştırmanın Uygulama Yeri: Araştırma, 2016-2017 öğretim yılı bahar döneminde Uludağ Üniversitesi Sağlık Bilimleri Fakültesi'nde gerçekleştirilmiştir.

Araştırmanın Evreni ve Örneklemi: Araştırmanın evrenini aynı dönem içinde hemşirelik programına kayıtlı olan $1,2,3$ ve 4. sınıf öğrencileri oluşturmuştur $(n=619)$. Çalışmada örneklem seçimine gidilmemiş, tüm öğrencilere ulaşılması hedeflenmiştir. Toplam 619 öğrencinin 486'sı çalışmaya katılmayı kabul etmiş ve evrenin \%79'una ulaşılmıştır.

Veri Toplama Araçları: Veriler, araştırmacı tarafından literatür taranarak oluşturulan; öğrencilerin cinsiyetini, kaçıncı sınıfta okuduklarını ve mezun oldukları liseyi sorgulayan sosyodemografik veri toplama formu ve SYBD II ölçek formu ile toplanmıştır.

Sağlıklı Yaşam Biçimi Davranışları Ölçeği II (SYBD II), 1987 yılında Pender ve arkadaşları tarafından geliştirilmiş, ölçeğin Türkiye'deki geçerlik ve güvenilirlik çalışması Esin (14) tarafından yapılmıştır. Daha sonra ölçeğin geçerlik ve güvenirlik çalışmasını Bahar ve arkadaşları (15) yapmıştır. Sağlıklı Yaşam Biçimi Ölçeği II, 52 maddeli ve 'hiçbir zaman', 'bazen', 'sık sık' ve 'düzenli olarak' seçeneklerini içeren 4'lü likert tipte bir ölçektir. Ölçek 'sağlık sorumluluğu', 'fiziksel aktivite', 'beslenme', 'manevi gelişim', 'kişilerarası ilişkiler' ve 'stres yönetimi' başlıkları altında altı alt ölçekten oluşmaktadır. Ölçekten alınan en düşük toplam puan 52, en yüksek toplam puan 208'dir. Toplam puan arttıkça, daha fazla sağlıklı yaşam biçimi davranışına sahip olduğu kabul edilmektedir (15). Çalışmamızda ölçeğin Cronbach Alpha katsayısı 0.92 olarak hesaplanmıştır.

Araştırmanın Uygulanması: Öğrencilere çalışma hakkında ön bilgilendirme yapıldıktan sonra çalışmaya katılmayı kabul eden öğrencilerden sözel onam alınmış ve sosyodemografik veri toplama formu ile SYBD II ölçek formu öğrencilere dağıtılmıştır. Ölçeğin ve sosyodemografik veri toplama formunun doldurulması için gerekli süre 10 dakikadır.

İstatistiksel Analiz: Çalışmadaki verilerin tanımlayıcı istatistikleri ve frekans dağılımları elde edilmiştir. Verilerin analizi için kullanılacak istatistiksel test/analizleri belirlemek amaciyla normallik ve varyansların homojenliği varsayımları sırasıyla Kolmogorov-Smirnov ve Levene testleri ile değerlendirilmiştir. Gruplar arası karşılaştırmalarda One Way ANOVA (post hoc: Bonferroni test) ve Student $t$ testi kullanılmıştır. Ölçeğin güvenirlik analizi yapılmış ve Cronbach alfa değeri hesaplanmıştır. İstatistiksel anlamlılık değeri olarak $\mathrm{p}<0.05$ kabul edilmiştir.

Araştırmanın Etik Yönü: Çalışmanın yapılabilmesi için Uludağ Üniversitesi Klinik Araştırmalar Etik Kurulu'ndan 14 Şubat 2017 tarihli ve 52588837-000/103 sayılı etik kurul izni, Uludağ Üniversitesi Sağlık Bilimleri Fakültesi Dekanlığından da 28.12.2016 tarihli ve 2016/7 sayılı çalışma izni alınmıştır. 


\section{BULGULAR}

Araştırmaya katılan öğrencilerin \%70.6'sı kadın, \%20.8'i 4. sınıf öğrencisi ve \%50.2'si Fen-Anadolu Lisesi mezunudur. Öğrencilerin sosyodemografik özellikleri ile ilgili bulgular Tablo 1'de verilmiştir.

Tablo 1. Öğrencilerin sosyodemografik özellikleri

\begin{tabular}{lcc}
\hline Sosyodemografik Özellikler & Sayı & \% \\
\hline Cinsiyet & & \\
Kadın & 343 & 70.6 \\
Erkek & 143 & 29.4 \\
\hline Sinıf & & \\
1. Sınıf & 120 & 24.7 \\
2. Sınıf & 125 & 25.7 \\
3. Sınıf & 101 & 20.8 \\
4. Sınıf & 140 & 20.8 \\
\hline Mezun Olunan Lise & & \\
Düz Lise & 106 & 21.8 \\
Sağlık Meslek Lisesi & 82 & 16.9 \\
Fen-Anadolu Lisesi & 244 & 50.2 \\
Diğer Liseler & 54 & 11.1 \\
\hline
\end{tabular}

Öğrencilerin SYBD II Ölçeği puan ortalamaları 131.02 \pm 18.98 'dir. Toplam ölçek puanının medyan değeri 130 olup minimum puan 83.00, maksimum puan 196'dır. Öğrencilerin SYBD II ölçeği ve alt boyutlarının tanımlayıcı istatistikleri Tablo 2'de verilmiştir.

Tablo 2. Öğrencilerin SYBD II ölçeği ve alt boyutlarının tanımlayıc istatistikleri $(\mathrm{n}=486)$

\begin{tabular}{lcccc}
\hline $\begin{array}{l}\text { SYBD II } \\
\text { Ölçeği Alt } \\
\text { Boyutları }\end{array}$ & $\overline{\mathbf{X}} \pm$ SS & $\mathbf{M}$ & Min. & Maks. \\
\hline $\begin{array}{l}\text { Sağlık } \\
\text { Sorumluluğu }\end{array}$ & $21.13 \pm 4.71$ & 21.00 & 10.00 & 36.00 \\
\hline $\begin{array}{l}\text { Fiziksel } \\
\text { Aktivite }\end{array}$ & $17.28 \pm 4.85$ & 17.00 & 8.00 & 32.00 \\
\hline Beslenme & $19.56 \pm 3.92$ & 19.00 & 9.00 & 33.00 \\
\hline $\begin{array}{l}\text { Manevi } \\
\text { Gelişim }\end{array}$ & $27.13 \pm 3.98$ & 27.00 & 16.00 & 36.00 \\
\hline $\begin{array}{l}\text { Kişileraras1 } \\
\text { İlişkiler }\end{array}$ & $26.13 \pm 4.11$ & 26.00 & 13.00 & 36.00 \\
\hline $\begin{array}{l}\text { Stres } \\
\text { Yönetimi }\end{array}$ & $19.76 \pm 3.59$ & 20.00 & 11.00 & 32.00 \\
\hline $\begin{array}{l}\text { SYBD II } \\
\text { Toplam } \\
\text { Puan }\end{array}$ & $\mathbf{1 3 1 . 0 2 \pm 1 8 . 9 8}$ & $\mathbf{1 3 0 . 0 0}$ & $\mathbf{8 3 . 0 0}$ & $\mathbf{1 9 6 . 0 0}$ \\
\hline SYBD II Sắ & & & & \\
\hline
\end{tabular}

SYBD II: Sağlıklı Yaşam Biçimi Davranışları II, X: Ortalama, SS: Standart Sapma, M: Medyan, Min: Minimum, Maks: Maksimum

Çalışma sonuçlarına göre öğrencilerin sosyodemografik özellikleri ile SYBD II Ölçek puan ortalamasına göre yapılan istatistiksel değerlendirmede, cinsiyet ile istatistiksel bir anlamlılık saptanmamıştır $(p>0.05)$. Sınıf düzeyinde yapılan istatistiksel değerlendirmede SYBD II ölçeği puan ortalamasına göre 3. sınıf öğrencilerinin puan ortalamalarının daha yüksek olması istatistiksel olarak anlamlı bulunurken $(\mathrm{p}<0.05)$; mezun olunan lise ile istatistiksel anlamlılık bulunmamıştır ( $p>0.05)$. SYBD II ölçeği alt boyut puan ortalamalarının öğrencilerin sosyodemografik özellikleri ile karşılaştırılma sonuçları Tablo 3 'te verilmiştir.

\section{TARTIŞMA}

Toplumun sağlık bakım gereksinimlerini karşılamak üzere eğitim alan hemşirelik öğrencilerinin sağlıklı yaşam biçimi davranışlarının yüksek olması beklenen bir durumdur (16). Bu çalışmanın sonucuna göre öğrencilerin SYBD II ölçeği puan ortalamaları 131.02 \pm 18.98 (yüksek) olarak bulunmuştur (Tablo 2). Hemşirelik öğrencileriyle yapılmış olan çalışmalara bakıldığında SYBD II ölçeği puan ortalamaları; Adıbelli ve arkadaşlarının (17) yaptıkları çalışmada $125.66 \pm 18.16, \quad$ Yıldırım ve arkadaşlarının (13) yaptıkları çalışmada 120.61 \pm 16.02 , Erzincanlı ve arkadaşlarının (2) yaptıkları çalışmada 126.61 18.00 , İlhan ve arkadaşlarının (18) yaptığ çalışmada $110.03 \pm 22.71$, Altun (19)'un çalışmasında $114.12 \pm 20.62$, Nassar ve Shaheen (20)'in yaptıkları çalışmada $127.24 \pm 21.03$ olarak rapor edilmiştir. Kuveyt'te yapılan bir çalışmada ise; hemşirelik öğrencilerinin sağlığı geliştirici yaşam biçimi davranışları düşük bulunmuştur (21). $\mathrm{Bu}$ sonuçlar göz önünde bulundurulduğunda çalışma grubumuzun SYBD II ölçeği puan ortalamasının daha yüksek olduğu söylenebilir. Çalışma grubunun SYBD II ölçeği puan ortalamasının daha yüksek olmasında, Uludağ Üniversitesi Sağlık Bilimleri Fakültesi Hemşirelik Bölümü'nde yürütülen eğitim programının ve öğrencilerin aldıkları derslerin etkili olduğu söylenebilir.

SYBD II ölçeği alt boyut puan ortalamalarına bakıldığında öğrenciler en yüksek puanı manevi gelişim, en düşük puanı fiziksel aktivite alt boyutundan almıştır (Tablo 2). Yapılan bazı çalışmalarda da benzer sonuç bulunmuştur $(1,4,10,11,13,19,22-24)$. Bu bulgu, öğrencilerin sportif faaliyetlere katılmadıklarını veya sağlıklı olmak için fiziksel aktivite yapma konusunda yetersiz oldukları sonucuna vardırmaktadır. Manevi gelişim puanının yüksek olması ise hemşirelik mesleğinin temel felsefesinde yatmakta olan insan sevgisi ve yardım etme güdüsü ile açıklanabilir.

Sınıf düzeyinin yükselmesine paralel olarak eğitim süresi arttıkça sağlıklı yaşam biçimi davranışları da artmaktadır. Literatürde eğitim düzeyinin sağlık davranışlarının gerçekleştirilmesinde etkili olduğu belirtilmiştir (25). Bu çalışmanın sonucunda 3. sınıf öğrencilerinin SYBD II ölçek puan ortalaması diğer sınıflara kıyasla daha yüksek bulunmuştur $(\mathrm{p}<0.001$; Tablo 3$)$. Yapılan bir çalışmada da benzer sonuç bildirilmiştir (17). Yapılan bazı çalışmalar 4. sınıf öğrencilerinin puan ortalamasının daha yüksek olduğunu rapor ederken $(1,10,11,26)$, bazıları ise sınıf düzeyi ile SYBD II ölçeği puan ortalaması arasında fark olmadığını göstermektedir $(4,5,27)$. Bu çalışmada 3 . sinıf öğrencilerinin 1., 2. ve 4. sinıf öğrencilerinden daha yüksek puana sahip olmalarının nedeninin, 3. sınıfların bahar yarıyılında yoğun katılımla aldıkları "Sağlık Eğitimi ve Sağlığ 1 Geliştirme" seçmeli dersi olduğu düşünülmektedir. Eğitim programı ve öğrencilerin aldıkları dersler, davranış değişimlerinde etkili olmaktadır. Bununla birlikte SYBD II ölçeği alt boyut puan ortalamalarına bakıldığında, 3. sınıf öğrencilerinin; sağlık sorumluluğu, fiziksel aktivite, beslenme ve stres yönetimi boyutlarındaki puan ortalaması da diğer 
Tablo 3. SYBD II ölçeği alt boyut puan ortalamalarının öğrencilerin sosyodemografik özellikleri ile karşılaştırılması

\begin{tabular}{|c|c|c|c|c|c|c|c|}
\hline Özellikler & $\begin{array}{c}\text { Sağlık Sorumluluğu } \\
\overline{\mathbf{X}} \pm \text { SS }\end{array}$ & $\begin{array}{c}\text { Fiziksel Aktivite } \\
\overline{\mathrm{X}} \pm \mathrm{SS} \\
\end{array}$ & $\begin{array}{c}\text { Beslenme } \\
\overline{\mathrm{X}} \pm \mathrm{SS} \\
\end{array}$ & $\begin{array}{c}\text { Manevi Gelişim } \\
\overline{\mathrm{X}} \pm \mathrm{SS} \\
\end{array}$ & $\begin{array}{c}\text { Kişilerarası } \\
\text { İliş̧kiler } \\
\overline{\mathrm{X}} \pm \mathrm{SS} \\
\end{array}$ & $\begin{array}{c}\text { Stres Yönetimi } \\
\overline{\mathrm{X}} \pm \mathrm{SS}\end{array}$ & $\begin{array}{l}\text { Toplam Puan } \\
\overline{\mathrm{X}} \pm \mathrm{SS} \\
\end{array}$ \\
\hline \multicolumn{8}{|l|}{ Sinıf } \\
\hline 1 & $20.57 \pm 4.81$ & $17.27 \pm 4.63$ & $19.13 \pm 3.76$ & $27.09 \pm 4.03$ & $25.72 \pm 4.11$ & $17.43 \pm 4.41$ & $129.56 \pm 18.71$ \\
\hline 2 & $20.20 \pm 4.64$ & $16.39 \pm 4.39$ & $18.60 \pm 3.32$ & $26.75 \pm 4.00$ & $25.67 \pm 4.00$ & $19.08 \pm 3.61$ & $126.70 \pm 17.60$ \\
\hline 4 & $21.80 \pm 4.64$ & $17.54 \pm 5.24$ & $20.54 \pm 4.26$ & $27.27 \pm 4.00$ & $26.67 \pm 4.01$ & $19.96 \pm 3.58$ & $133.83 \pm 20.19$ \\
\hline $\mathbf{p}^{*}$ & $0.005^{*}$ & $0.022 *$ & $<0.001 *$ & 0.714 & 0.813 & $0.042 *$ & $0.002 *$ \\
\hline Post hoc** & $(2-3) ;(2-4)$ & $(2-3)$ & $(1-3) ;(2-4)$ & - & - & $(2-3)$ & $(2-3) ;(2-4)$ \\
\hline Kadın & $21.39 \pm 4.66$ & $16.87 \pm 4.54$ & $19.90 \pm 3.79$ & $27.32 \pm 3.87$ & $26.37 \pm 4.05$ & $19.94 \pm 3.41$ & $131.81 \pm 18.20$ \\
\hline $\mathbf{p}^{* * *}$ & 0.029 & 0.016 & 0.001 & 0.077 & 0.038 & 0.047 & 0.052 \\
\hline \multicolumn{8}{|c|}{ Mezun Olunan Lise } \\
\hline Düz & $21.61 \pm 4.53$ & $17.35 \pm 5.24$ & $20.01 \pm 4.00$ & $27.29 \pm 4.21$ & $26.29 \pm 4.14$ & $19.95 \pm 3.51$ & $132.52 \pm 20.35$ \\
\hline Sağlık Meslek & $21.96 \pm 4.96$ & $17.78 \pm 5.11$ & $20.34 \pm 3.98$ & $28.17 \pm 3.72$ & $27.34 \pm 4.22$ & $20.28 \pm 3.65$ & $135.87 \pm 19.77$ \\
\hline Fen-Anadolu & $20.77 \pm 4.77$ & $17.19 \pm 4.70$ & $19.26 \pm 3.88$ & $26.70 \pm 3.97$ & $25.82 \pm 3.98$ & $19.54 \pm 3.61$ & $129.30 \pm 18.39$ \\
\hline Diğer & $20.53 \pm 4.25$ & $16.83 \pm 4.39$ & $18.87 \pm 3.63$ & $27.20 \pm 3.72$ & $25.38 \pm 4.21$ & $19.62 \pm 3.57$ & $128.46 \pm 16.32$ \\
\hline $\mathbf{p}$ & 0.160 & 0.770 & 0.058 & 0.713 & 0.333 & 0.547 & 0.065 \\
\hline
\end{tabular}


sınıflardan istatistiksel olarak daha yüksek bulunmuştur $(\mathrm{p}<0.001$; Tablo 3).

Geleneksel kültürümüzde kadına biçilen toplumsal roller çerçevesinde kadınların kendilerine ve çevrelerine karşı daha koruyucu tutum sergilemesi, daha az riskli davranış göstermesi ve sağlık davranışlarının daha iyi olması beklenen bir durumdur (26). Bu çalışmanın sonucunda ise SYBD II ölçeği puan ortalamaları ile öğrencilerin cinsiyetleri arasında istatistiksel anlamlılık yoktur ( $>00.05$; Tablo 3 ). Yapılan bazı çalışmalarda da benzer sonuç bildirilmiştir $(17,27,28)$. Bazı çalışmalarda ise kadın öğrencilerin SYBD II ölçek puan ortalamalarının erkek öğrencilerden yüksek olduğu rapor edilmiştir $(2,4,6,20,26)$. Çalışma sonucunun; son yüzyılda küresel sermaye piyasasının getirdiği şartlar nedeniyle kadının çalışma hayatında erkekle aynı yükü paylaşıyor olmasından ötürü sergiledikleri/sergileyemedikleri sağlıklı yaşam biçimi davranışlarından kaynaklandığ düşünülmektedir. Ancak çalışmamızda kadın öğrencilerin; sağlık sorumluluğu, beslenme, kişilerarası ilişkiler ve stres yönetimi puan ortalamalarının, erkek öğrencilerin ise egzersiz puan ortalamalarının anlamlı düzeyde yüksek olduğu tespit edilmiştir $(p<0.05$; Tablo 3). $\mathrm{Bu}$ durumun nedeni kadının aile içindeki rolüyle ve sosyal ilişkilerde erkeklere göre paylaşıma daha açık olmasıyla, erkeklerin ise spor faaliyetlerine daha meraklı ve ilgili olmalarıyla açıklanabilir. Yapılan bazı çalışmalarda da benzer sonuç bildirilmiştir $(4,17,20,26)$.

$\mathrm{Bu}$ çalışmada SYBD II ölçek puan ortalaması ve alt boyutları ile mezun olunan lise arasında istatistiksel olarak anlamlılık bulunmamıştır ( $\mathrm{p}>0.05$; Tablo 3). Yapılan bir çalışmada da benzer sonuç bildirilmiştir (6). Mezun olunan lisenin çalışma sonuçları üzerinde fark yaratmamasında; lise çağındayken çocukların çok büyük bir kısmının aile yanında kalması ve sağlık davranışlarının-sağlıklı yaşama biçimlerinin çoğunlukla aile tarafından sağlanması etkili olmuş olabilir.

\section{SONUÇ}

Çalışma sonucumuza göre öğrencilerin SYBD II ölçek puan ortalamalarının yüksek düzeyde olduğu görülmüştür. SYBD II ölçeğinin alt boyutları incelendiğinde ise öğrencilerin en yüksek puanı manevi gelişim, en düşük puanı ise fiziksel aktivite alt boyutundan aldıkları belirlenmiştir. Özellikle 3. sınıf öğrencilerinin SYBD II ölçeği puan ortalaması diğer sinıflardan yüksek bulunurken, cinsiyet ve mezun olunan lise ile ölçek puan ortalaması arasında anlamlı bir ilişki bulunamamıştır. $\mathrm{Bu}$ sonuçlar doğrultusunda; sağlığın geliştirilmesinde, olumlu sağlık davranışlarının hemşirelere kazandırılması için hemşirelik eğitiminde müfredatın bu davranışları kazandırmaya ağırlık verecek şekilde düzenlenmesi, öğrencilerin sportif faaliyetlere yönlendirilmesi, sağlık davranışları ve sağlıklı yaşam biçimi davranışları üzerinde etkili olan faktörlere yönelik daha geniş örneklemi kapsayan araştırmaların yapılması önerilmektedir.

\section{KAYNAKLAR}

1. Aksoy T, Uçar H. Hemşirelik Öğrencilerinin Sağlıklı Yaşam Biçimi Davranışları. Hacettepe Üniversitesi Hemşirelik Fakültesi Derg [Internet]. 2014 [Erişim tarihi: 2017 Aug 22]; 1(2): 53-67. Erişism adresi: http://dergipark.ulakbim.gov.tr/hunhemsire/article/vie w/5000154752/0.

2. Erzincanlı S, Zaybak A, Khorshid L. Hemşirelik Öğrencilerinin Sağlıklı Yaşam Biçimi Davranışları ve Zaman Yönetimi Becerileri. Ege Üniversitesi Hemşirelik Fakültesi Derg [Internet]. 2015 [Erişim tarihi: 2017 Aug 22]; 31(2): 8-25. Erişim adresi: http://hemsirelik.ege.edu.tr/files/372015.pdf.

3. Özvarış ŞB. Sağlık Eğitimi ve Sağlığı Geliştirme. Güler Ç, Akın L, editörler. Halk Sağlığı - Temel Bilgiler [Internet]. 3. Bask1. Ankara: Hacettepe Üniversitesi Yayınları; 2015 [Erişim tarihi: 2017 Aug 22]. Erişim adresi: https://www.hacettepe.web.tr/halksagligi-temel-bilgiler-hacettepe.

4. Tambağ H. Hatay Sağlık Yüksekokulu Öğrencilerinin Sağlıklı Yaşam Biçimi Davranışları ve Etkileyen Faktörler. Hacettepe Üniversitesi Sağlık Bilim Fakültesi Hemşirelik Derg [Internet]. 2011 [Erişim tarihi: 2017 Aug 22]; 18(2): 47-58. Erişim adresi: http://dergipark.gov.tr/download/article-file/88498.

5. Yılmazel G, Çetinkaya F, Naçar M. Hemşirelik Öğrencilerinde Sağlığı Geliştirme Davranışları. TAF Prev Med Bull [Internet]. 2013 [Erişim tarihi: 22 Ağustos 2017]; 12(3): 261-70. Erişim adresi: https://www.researchgate.net/publication/255988658_ 4_Yilmazel_G_Cetinkaya_F_Nacar_M_Hemsirelik_ Ogrencilerinde_Sagligi_Gelistirme_Davranislari_TA F_Prev_Med_Bull_2013123261-270.

6. Özyazıcıoğlu N, Kılıç M, Erdem N, Yavuz C, Afacan S. Hemşirelik öğrencilerinin sağlıklı yaşam biçimi davranışlarının belirlenmesi. Uluslararası İnsan Bilim Derg [Internet]. 2011 [Erişim tarihi: 22 Ağustos 2017]; 8(2): 277-332. Erişim adresi: http://www.insanbilimleri.com.

7. Alpar ŞE, Şenturan L, Karabacak Ü, Sabuncu N. Change in the health promoting lifestyle behaviour of Turkish University nursing students from beginning to end of nurse training. Nurse Educ Pract [Internet]. 2008 [Cited: 2017 Aug 22]; 8(6): 382-8. Erişim adresi:http://linkinghub.elsevier.com/retrieve/pii/S147 1595308000346.

8. Bryer J, Cherkis F, Raman J. Health-promotion behaviors of undergraduate nursing students: A survey analysis. Nurs Educ Perspect [Internet]. 2013 [Cited: 2017 Aug 22]; 34(6): 410-5. Available from: http://www.ncbi.nlm.nih.gov/pubmed/24475604.

9. Güner İC, Demir F. Ameliyathane Hemşirelerinin Sağlıklı Yaşam Biçimi Davranışlarının Belirlenmesi. 4. Ulusal Cerrahi ve Ameliyathane Hemşireliği Kongresi; 22-26 Ekim 2003; İzmir;

10. Ulaş Karaahmetoğlu G, Soğuksu S, Kaçan Softa H. Hemşirelik 1. ve 4. Sınıf Öğrencilerinin Sağlıklı Yaşam Biçimi Davranışları ve Etkileyen Faktörlerin İncelenmesi. Erciyes Üniversitesi Sağlık Bilim Fakültesi Derg [Internet]. 2014 [Erişim tarihi: 22 Ağustos 2017]; 2(2): 26-42. Erişim adresi: http://sbfedergi.erciyes.edu.tr/article/view/1051000118.

11. Açıksöz S, Uzun S, Arslan F. Relationship Between Perceptions of Health Status and Health Promotion Behaviors in Nursing Students. Gulhane Med J [Internet]. 2013 [Cited: 2017 Aug 22]; 55(3): 181. Available from: http://www.scopemed.org/fulltext pdf.php?mno=15228. 
12. Whitehead D. Health promoting hospitals: The role and function of nursing. J Clin Nurs [Internet]. 2005 [Cited: 2017 Aug 22]; 14(1): 20-7. Available from: http://www.ncbi.nlm.nih.gov/pubmed/15656844.

13. Yıldırım N, Aydın M, Hayırsever F, Ankaralı H. Bir Hemşirelik Lisans Programında Verilen Sağlığ Geliştirme Dersinin Etkinliği. Dokuz Eylül Üniversitesi Hemşirelik Fakültesi Elektron Derg [Internet]. 2016 [Erişim tarihi: 22 Ağustos 2017]; 9(3): 88-92. Erişim adresi: http://www.deuhyoedergi.org.

14. Esin N. Endüstriyel Alanda Çalışan İşçilerin Sağlık Davranışlarının Saptanması ve Geliştirilmesi [Doktora Tezi]. İstanbul: İstanbul Üniversitesi; 1997.

15. Bahar Z, Beşer A, Gördes N, Ersin F, Kissal A. Sağlıklı Yaşam Biçimi Davranışları Ölçeği II'nin Geçerlik ve Güvenirlik Çalışması. Cumhur Üniversitesi Hemşirelik Yüksekokulu Derg [Internet]. 2008 [Erişim tarihi: 22 Ağustos 2017]; 12(1): 1-13. Erişim adresi: http://eskidergi.cumhuriyet.edu.tr /makale /1723.pdf.

16. Bostan N, Beşer A. Hemşirelerin Sağlıklı Yaşam Biçimi Davranışlarını Etkileyen Faktörler. Hemşirelikte Eğitim ve Araştırma Derg [Internet]. 2017 [Erişim tarihi: 9 Kasım 2018]; 14(1): 38-44. Erişim adresi: https://www.journalagent.com/kuhead /pdfs/KUHEAD_14_1_38_44.pdf.

17. Adıbelli D, Olğun S, Turan GS. Hemşirelik Öğrencilerinin Sağlıklı Yaşam Biçimi Davranışları ve Etkileyen Faktörler. Cumhur Hemşirelik Derg [Internet]. 2017 [Erişim tarihi: 22 Ağustos 2017]; 6(1): 8-17. Erişim adresi: http://dergi.cumhuriyet.edu.tr/cumunuj/article/view/5 000152829.

18. İlhan N, Bahadırlı S, Ercan Toptaner N. Üniversite öğrencilerinin ruhsal durumları ile sağlık davranışları arasındaki ilişkinin belirlenmesi. Marmara Üniversitesi Sağlık Bilim Enstitüsü Derg [Internet]. 2014 [Erişim tarihi: 22 Ağustos 2017]; 4(4): 207-15. Erişim adresi: http://e-dergi.marmara.edu.tr/marusbed /article/view/5000116997/0.

19. Altun I. Effect of a health promotion course on health promoting behaviours of university students. East Mediterr Heal J [Internet]. 2008 [Cited: 2017 Aug 23]; 14(4): 880-7. Available from: http://akademikpersonel.kocaeli.edu.tr/ialtun/diger/ialt un18.08.2010_16.48.05diger.pdf

20. Nassar OS, Shaheen AM. Health-Promoting Behaviours of University Nursing Students in Jordan. Health (Irvine Calif) [Internet]. 2014 [Cited: 2017 Aug 23]; 6(6): 2756-63. Available from: http://www.scirp.org/journal/health

21. Al-Kandari F, Vidal VL. Correlation of the healthpromoting lifestyle, enrollment level, and academic performance of College of Nursing students in Kuwait. Nurs Health Sci [Internet]. 2007 [Cited: 2017 Aug 23]; 9(2): 112-9. Available from: http://www.ncbi.nlm.nih.gov/pubmed/17470185.

22. Çetiner H, Ulupınar S. Sağlık Profesyoneli Olan ve Olmayan Hastane Çalışanlarının Sağlıklı Yaşam Biçimi Davranışları. STED [Internet]. 2018 [Erişim tarihi: 27 Haziran 2018]; 27(1): 1-10. Erişim adresi: http://dergipark.gov.tr/download/article-file/455832.
23. Ayaz S, Tezcan S, Akıncı F. Hemşirelik Yüksekokulu Öğrencilerinin Sağlığı Geliştirme Davranışları. Cumhur Üniversitesi Hemşirelik Yüksek Okulu Derg. 2005; 9(2): 26-34.

24. Ertop NG, Yılmaz A, Erdem Y. Üniversite Öğrencilerinin Sağlıklı Yaşam Biçimleri. Kırıkkale Üniversitesi Tıp Fakültesi Dergisi. 14(2): 1-7.

25. Walker N, Volkan K, Sechrist K. Health promoting life styles of older adults: Comparisons with young and middle - aged adults, correlates and patterns. Adv Nurs Sci. 1988; 11(1): 76-90.

26. İlhan N, Batmaz M, Akhan LU. Üniversite Öğrencilerinin Sağlıklı Yaşam Biçimi Davranışları. Maltepe Üniversitesi Hemşirelik Bilim ve Sanatı Derg [Internet]. 2010 [Erişim tarihi: 22 Ocak 2018]; 3(3): 35-43. Erişim adresi: https://hemsirelik.maltepe.edu.tr /dergiler/8sayi/pdf/34-44.pdf.

27. Hosseini M, Ashktorab T, Taghdisi MH, Vardanjani AE, Rafiei H. Health-Promoting Behaviors and their Association with Certain Demographic Characteristics of Nursing Students of Tehran City. Glob J Health Sci [Internet]. 2015 [Cited: 2017 Aug 23]; 7(2): 264-72. Available from: http://www.ccsenet.org/journal/index.php/gjhs/article/ view/38566/23119.

28. Yılmazel G, Çetinkaya F, Naçar M. Hemşirelik Öğrencilerinde Sağlığı Geliştirme Davranışları. TAF Prev Med Bull [Internet]. 2013 [Erişim tarihi: 22 Ağustos 2017]; 12(3): 261-70. Erişim adresi: http://www.ejmanager.com/fulltextpdf.php?mno=188 56. 